\title{
Abusive supervision and employee silence: The mediating effect of perceptions of organizational politics and the moderating effect of LMX
}

Huang Ai-Hua

South China University of Technology

Li Yang

South China University of Technology

Guo Guo-Tao

South China University of Technology

\section{Recommended Citation}

Ai-Hua, H., Yang, L., \& Guo-Tao, G. (2018). Abusive supervision and employee silence: The mediating effect of perceptions of organizational politics and the moderating effect of LMX. International Interdisciplinary Business-Economics Advancement Journal, 3(1), 19-27.

\section{Revisions}

Submission date: Jan. 6, 2017

1st Revision: Oct. 11, 2017

2nd Revision: Oct. 27, 2017

3rd Revision: Nov. 8, 2017

4th Revision: Nov. 10, 2017

Acceptance: Dec. 21, 2017 


\title{
Abusive Supervision and Employee Silence: The Mediating Effect of Perceptions of Organizational Politics and the Moderating Effect of LMX
}

\author{
Huang Ai-Hua ${ }^{1}$, Li Yang ${ }^{2}$, and Guo Guo-Tao ${ }^{3}$ \\ School of Business Administration \\ South China University of Technology, China \\ ${ }^{1}$ huangaihua126@126.com \\ 286628717@qq.com \\ 3793894184@qq.com
}

\begin{abstract}
Based on the conservation of resources theory this paper explores the mediating effect of perceptions of organizational politics on the relationship between abusive supervision and employee silence. We also explore the moderating effect of leader-member exchange in the relationship between abusive supervision and perceptions of organizational politics. In total, 560 junior employees were sampled through questionnaire. The results indicated that perceptions of organizational politics mediated the relationship between abusive supervision and employee silence. In addition, leader-member exchange moderated the relationship between abusive supervision and employee silence. It was also found that abusive supervision demonstrated a stronger positive influence on perceptions of organizational politics for those who have a poor quality of leader-member exchange.
\end{abstract}

Keywords: abusive supervision, organizational politics, perceptions of organizational politics, employee silence, leader-member exchange

\section{Introduction}

As a typical behavior of negative leadership, abusive supervision has received wide attention in China and abroad in recent years. Abusive supervision refers to subordinates perceptions of the extent to which supervisors engage in the sustained display of hostile verbal and nonverbal behaviors, excluding physical contact" (Tepper, 2000). As so far, scholars have analyzed the harm roles that abusive supervision played on organizations and staffs from multiple perspectives. Firstly, from the individual perspective, existing research has shown that abusive supervision plays a significantly negative effect on employees' work and life, causing emotional exhaustion, decreasing the sense of psychological security (Whitman, 2014), reducing job satisfaction (Yukl, 2002), job performance (Hoobler \& Brass, 2006) and employee creativity (Liu \& Liao, 2012), increasing turnover intention (Whitman, 2014), and even causing counter productive work behavior (Tepper, Henle, Lambert, Giacalone, \& Duffy, 2008). Secondly, from the group perspective, Wu, Liu, Leung, \& Wu (2013) found that abusive supervision would 
reduce team performance by reducing management team communication and team effectiveness. Priesemuth, Schminke, Ambrose, \& Folger (2014) also found that an abusive supervision atmosphere affects group cooperation and organizational citizenship behavior through group identity, and it also influences the group performance through the group efficiency (Priesemuth et al., 2014).

However, most of the previous studies focused on the relationship between abusive supervision and employees' explicit behavior. In fact, there are big differences from western theories which think subordinates and leaders have an equal status. In Chinese situation, it is obvious that leaders have some power to the subordinates. Therefore, employees are more likely to take a subtle way to express their grievances or revenge their leaders, such as keeping silent. Liu and Liu (2014) refers that abusive supervision may cause employees to feel organizational politics and this perception of organizational politics may cause employees to keep silence.

In general, the supervisors implement abusive supervision with some purposes. For example, the supervisors want to maintain personal dignity and influences. This style of leadership can also be regarded as a political act taken by a manager in order to maintain personal authority (Liu \& Liu, 2014). Encountering this kind of political behaviors, the subordinates usually react in two ways: (1) falling into the organizational politics to change the original political distribution, and (2) avoiding organizational politics to reduce resources depletion, such as keeping silent and reducing organizational citizenship behavior. When encountering abusive supervision, the subordinates would perceive insulted and increase their perceptions of organizational politics, which may threaten and cause their loss of emotional resources, such as self-esteem and selfconfidence. According to the conservation of resources theory, people usually try to access to their own physical and emotional resources and protect them.

The first principle of the conservation of resources theory is that loss of resources is more important than accessing to the resources. Therefore, avoiding organizational politics is more important than falling into it, and the subordinates tend to keep silent to consolidate the existing resources. In other words, abusive supervision enhances the subordinate perception of organizational politics and results in employee silence.

So, whether the effects will be differed for different subordinates? According to the contingency theory of leadership, the effectiveness of leadership largely depends on the situation, so it must consider matching the situation elements. Thus, this paper focuses on two issues: firstly, this paper explores the mediating effect of perceptions of organizational politics on the relationship between abusive supervision and employee silence; secondly, this paper explores the moderating effect of leader-member exchange on the relationship between abusive supervision and perceptions of organizational politics. The research framework is shown in figure 1:

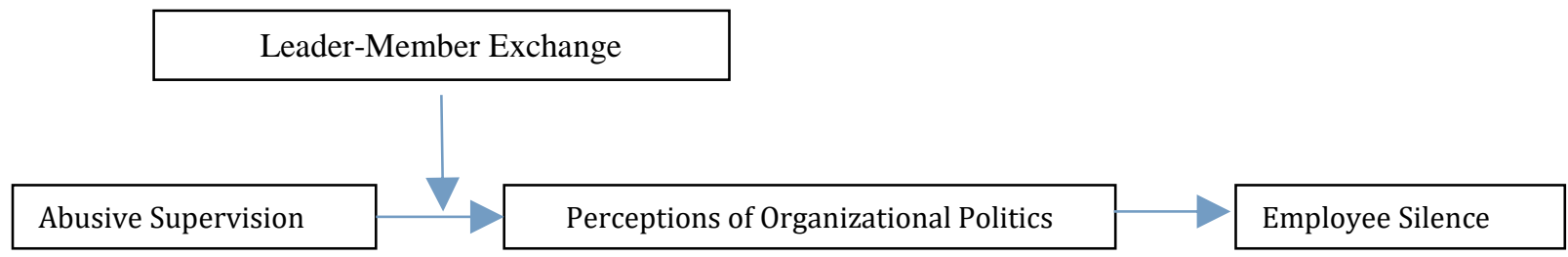

Figure 1: Research framework 


\section{Literature Review}

\section{Abusive Supervision and Employee Silence}

Firstly, proposed by Morrison and Milliken in 2000, employee silence was defined as the behavior that the employees retain personal views about the problems existed in the organization. Dyne, Aiig and Boterolc (2003) believed that employee silence was not the opposite of employee voice behavior, buta behavior that employee behaved after weighing self-interests and careful considerations. In other words, before keeping silence, employees must have understood something about the events. The employee who keep silence but lack of understanding it does not belong to the category of employee silence.

Various research has been conducted to understand the antecedents of employee silence. It was found that leadership style was the key factor causing employee silence. Morrison and Milliken (2000) argued that employee silence was rooted by implicit management concept of the top managers and fear to face the negative feedback. However, as atypical form of negative leadership, what abusive supervision advocates are authority, high pressure and despising subordinate's voice. As a result, this leadership actually passed informing the subordinates that the leader is not interested in their advice. Instead, leaders may consider this behavior as a way that employees oppose their leadership, and thus abuse more to the subordinates. Therefore, this paper puts forward the following hypothesis:

- Hypothesis 1: Abusive supervision has a significantly predictive effect on employee silence.

\section{The Mediating Effect of Perceptions of Organizational Politics}

In general, the organizational politics refer to a sense of shared management. The core is to guide others to evaluate and explain events so that they can get what they want. And the perceptions of organizational politics refer to a subjective feeling and evaluation about this kind of selfinterested behavior. Wu (2001) conducted a localization research on perceptions of organizational politics and found that supervisor's behavior is an important dimension of perceptions of organizational politics. Thus, the perception of supervisor's political intention of leadership behavior is an important source of employees' perceptions of organizational politics. The supervisors who abuse their subordinates with purposes, such as raising the personal influence or excluding outsider. Therefore, abusive supervision is also a kind of political behavior. And when the subordinate perceives abusive supervision from his/her supervisor, the perceptions of organizational politics will be enhanced. Furthermore, abusive supervision often accompanies with increased organizational centralization, destroy organizational trust atmosphere and lack subordinate resources. Ma (2005) has identified the antecedents of perceptions of organizational politics, including the lack of resources, trust atmosphere, centralization and formalization. Therefore, this paper puts forward the following hypothesis:

- Hypothesis 2: Abusive Supervision has a significantly positive influence on perceptions of organizational politics. 
According to the conservation of resources theory, individuals would try to obtain and maintain their existing resources instinctively. Individuals will feel stressful and unsafe, when perceiving a possibility of losing resources or being hard to get new resources in the working environment (Hobfoll, 1989). And the increase of perceptions of organizational politics caused by abusive supervision will make employees become more sensitive to supervisor's behavior and enlarge this kind of insecurity. Therefore, based on the conservation of resources theory, perceptions of organizational politics may cause loss of employee's resources, such as employee self-esteem, job insecurity and the emotional commitment. Besides, the principle of resource depletion shows that compared to obtain new resources, the individuals whose resources are losing will be more worried about a further loss of resources.

Therefore, the threat of losing resources will make subordinates prefer to protect their existing resources, rather than get new resources. Employee silence is a conservative strategy that employees take to protect existing resources when they have a clear awareness of the surrounding environment so that employees feel a sense of control of their resources. Therefore, this paper puts forward the following hypothesis:

- Hypothesis 3: Perceptions of organizational politics play a mediating effect on the relationship between abusive supervision and employee silence.

\section{The Moderating Effect of Leader-Member Exchange}

Leader-member exchange theory (LMX theory) is an important leadership theory about exchange relationships between supervisors and the subordinates in organizations. This theory refers that, to different subordinates, leaders have a different LMX, which will influence their management style. In general, the social exchange relationship can be divided into two categories: high-quality exchanges (also called "in-group") and low-quality exchanges (also called "out-group"). "In-group" means that some subordinates establish a special relationship with leaders and tend to get more care from leaders, such as more information, more trust and so on. On the contrary, "out-group" means those subordinates just establish a common exchange relationship based on formal rights. This kind of phenomenon is especially significant in China where it emphasizes relationships. The employees who are in-group can not only get support from the leaders on the work, but also get a lot of attention even in private life. The role of leaders is more like a big brother rather than a supervisor. Therefore, the subordinate may react differently to the same management behavior due to different leader-member exchange relationships. For the "in-group", since the supervisors and subordinate trust each other and communicate smoothly, the subordinate can always understand the implications of the abused behavior. In contrast, for the "out-group", they cannot grasp information so well and do not have a good relationship with their leaders, so they often have a sense of tension and tend to link the abusive behavior to political behavior when get abused. Some would even evaluate the political implications of the abusive behavior actively and take actions to consolidate their own resources. Therefore, this paper puts forward the following hypothesis:

- Hypothesis 4: Leader-member exchange plays a moderated role in the relationship between abusive supervision and perceptions of organizational politics. Specifically, for those who have low-quality exchanges, the impact of abusive supervision on perceptions of organizational politics is relatively strong. 


\section{Methodology}

\section{Sample}

The respondents in this study are mid-level employees with a direct leader in their organization. The data were collected using questionnaires. To avoid the effects of homologous variance, the surveys were conducted twice with a month interval. The first survey investigated abusive supervision, leader-member exchange and perceptions of organizational politics. The second survey collected demographic variables and employee silence behavior. 600 questionnaires were distributed, and 560 effective questionnaires were collected. In total, the number male respondents are $316(56.4 \%)$, and the number of female is $244(43.6 \%)$. The ages of respondents are mainly in 16-24 (52.3\%) and 25-30 (43.1\%) years old. Most respondents are undergraduates $(86.2 \%)$. Their working years are mainly under 1 year $(32.1 \%)$ and 1 to 3 years $(43.3 \%)$.

\section{Measures}

This study used the abusive supervision scale (15-item scale) developed by Tepper in 2000 . This scale has been translated into Chinese by Wu (2005), and applied in Chinese context (Aryee, Chen, Sun, \& Debrah, 2007). The result in this study shows that an internal consistency with are liability coefficient of 0.91 (> 0.70).

This study employed the 15-item scale of perceptions of organizational politics developed by Ma (2005) in Chinese context. The result shows a reliability coefficient of 0.85 . The 16-item leadermember exchange scale used in this study was developed by Wang and Niu (2004) in Chinese context. The scale has showed a good reliability and validity in previous research. The reliability coefficient in this study is 0.95 . The 16-item scale of employee silence was developed by Zheng, Ke, Shi, \& Zheng (2008) in Chinese context. The result shows a reliability coefficient of 0.92 .

\section{Findings}

Table 1 shows the mean, standard deviation and correlation coefficient of the main variables. The abusive supervisions significantly correlated with perceptions of organizational politics $(r=0.57, p<0.01)$ and employee silence $(r=0.31, p<0.05)$. Besides, perceptions of organizational politics and employee silence are also significantly positive correlated $(r=0.55, p<0.01)$. The results provide a preliminary validation of our hypotheses.

Table 1: Descriptive Statistics and Correlations

\begin{tabular}{lllllllll}
\hline Variables & 1 & 2 & 3 & 4 & AS & LMX & POP & ES \\
\hline Gender & 1 & & & & & & & \\
Age & $-0.35^{* *}$ & 1 & & & & & & \\
Years of working & 0.07 & $0.32^{* *}$ & 1 & & & & & \\
Education & 0.00 & -0.18 & $-0.27^{*}$ & 1 & & & & \\
Abusive supervision & $-0.27^{*}$ & 0.15 & -0.11 & 0.22 & 1 & & & \\
LMX & -0.00 & 0.00 & -0.04 & 0.01 & $-0.65^{* *}$ & 1 & & \\
Perceptions of organizational politics & 0.10 & -0.16 & 0.05 & -0.16 & $0.57^{* *}$ & $-0.55^{* *}$ & 1 & \\
Employee silence & 0.13 & -0.18 & 0.07 & -0.18 & $0.31^{*}$ & $-0.45^{*}$ & $0.55^{*}$ & 1 \\
Mean & 1.43 & 1.53 & 1.85 & 3.0 & 2.27 & 3.28 & 2.98 & 3.11 \\
Standard deviation & 0.50 & 0.63 & 0.56 & 0.56 & 0.94 & 0.84 & 0.59 & 0.70 \\
\hline
\end{tabular}


Table 2 shows the hierarchical regression analysis results. After controlling the population statistical variables, the results indicate that: (1) abusive supervision has positively significant influences on employee silence $(\beta=0.48, \mathrm{P}<0.01)$, which supports hypothesis 1 ; $(2)$ abusive supervision has positively significant influences on perceptions of organizational politics $(\beta=0.69, \mathrm{P}<0.01)$, which supports hypothesis 2 . According to the research of Baron and Kenny (1986), the mediating role of perceptions of organizational politics can be justified. Abusive supervision has positively significant influences on employee silence (M2: $\beta=0.48, \mathrm{P}<0.01$, M5: $\beta=0.69, \mathrm{P}<0.01)$.However, when the variable of perceptions of organizational politics enters into the regression equation, the relationship between them is weakened (from $M 2, \beta=0.48, p<0.01$, down to $\mathrm{M} 3, \beta=0.29, \mathrm{p}<0.01$ ), indicating that the perceptions of organizational politics play a mediating effect on the relationship between abusive supervision and employee silence, which supports hypothesis 3. As for the moderating effect of LMX, M7 model indicates that the interaction between abusive supervision and LMX would have a negative impact on perceptions of organizational $(\mathrm{M} 7: \beta=-0.14, \mathrm{P}<0.05)$. In other words, the better the quality of leader-member exchange relationship is, the positive influence on perceptions of organizational that abusive supervision play is weaker. In order to reflect the moderating effects of LMX more directly, according to the steps provided by Aiken, West, and Reno (1991), the interaction plot of abusive supervision and perceptions of organizational politics was shown in figure 2. When confronted with abusive supervision, high-quality LMX members would perceive organizational politics less than low-quality LMX members, which supports hypothesis 4.

Table 2: The Results of Hierarchical Regression

\begin{tabular}{|c|c|c|c|c|c|c|c|}
\hline Model & Emplc & e silence & & Perce & ons of org & zational & \\
\hline & M1 & M2 & M3 & M4 & M5 & M6 & M7 \\
\hline Gender & 0.07 & 0.19 & 0.08 & 0.04 & 0.02 & 0.18 & 0.02 \\
\hline Age & -0.22 & -0.28 & -0.14 & -0.16 & $-0.25 *$ & -0.23 & -0.00 \\
\hline Years of working & 0.12 & 0.15 & 0.08 & 0.09 & -0.5 & 0.11 & 0.01 \\
\hline Education & 0.14 & 0.02 & 0.05 & 0.12 & 0.12 & -0.03 & -0.00 \\
\hline Abusive Supervision & & $0.48 * *$ & $0.29 * *$ & & $0.69 * *$ & $0.55 * *$ & $0.54 * *$ \\
\hline $\begin{array}{l}\text { Perceptions of } \\
\text { organizational politics }\end{array}$ & & & $0.57 * *$ & & & & \\
\hline LMX & & & & & & $-0.32 * *$ & $-0.32 * *$ \\
\hline Abusive Supervision *LMX & & & & & & & $-0.14 *$ \\
\hline $\mathrm{R}^{2}$ & 0.07 & 0.21 & 0.32 & 0.05 & 0.47 & 0.49 & 0.30 \\
\hline$\Delta \mathrm{R}^{2}$ & 0.00 & 0.14 & 0.26 & -0.01 & 0.42 & 0.43 & 0.26 \\
\hline $\mathrm{F}$ & 1.06 & $3.12 *$ & $4.72 * *$ & 0.80 & $10.45 * *$ & $9.19 * *$ & $7.62 * *$ \\
\hline
\end{tabular}

Note: * means $\mathrm{P}<0.05$, ** means $\mathrm{P}<0.01, * * *$ means $\mathrm{P}<0.001$

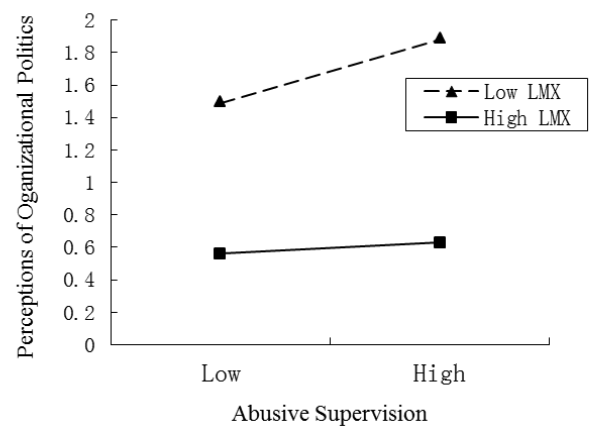

Figure 2: Abusive supervision and perceptions of organizational politics moderated by LeaderMember Exchange relationships 


\section{Conclusions}

Based on the conservation of resources theory, the paper discussed the effects of abusive supervision on employee silence from the perspective of organizational politics. The study found that: (1) abusive supervision has a positively significant influence on employee silence; (2) perceptions of organizational politics play a partial mediating effect on the relationship between abusive supervision and employee silence; and (3) leader-member exchange relationships plays a moderating role on the relationships between abusive supervision and perceptions of organizational politics.

Firstly, the paper assumed and verified that abusive supervision has positively significant influences on employee silence. According to the reciprocal principle of social exchange theory, when the leader supports employees with positive behavior such as active guide and authorization, the employees will work hard in return. In contrast, when the leader urges employees with negative behavior such as threats and abuse, the employees will return in a negative way. However, as the subordinate, it is clearly undesirable for them to response headon confrontation towards abuse supervision, as the leaders are the decision-makers of resources allocation. As a result, the employees usually choose to keep silent to vent their dissatisfaction of abusive supervision and to protect themselves. Thus, it can be inferred that employee silence is a behavior trying to protect themselves and to avoid working, bringing a negative influence to the organization. For individuals the silence can express their dissatisfaction about abusive behavior in the short term, while it can also prevent communications and feedback from their supervisors in the long term, resulting in poor job performances and even leading to more abusive behaviors.

Secondly, the study confirmed that perceptions of organizational politics play a partial mediating effects on the relationship between abusive supervision and employee silence from the unique perspective of organizational politics. Researchers used to explore the influences of abusive supervision from the perspectives of equity theory and the psychological security. Therefore, this study not only enriches the research of organizational politics and abusive behavior, but also widens the dependent variable perspective of organizational politics. Besides, this paper shows that the enhancement of perceptions of organizational politics can lead to employee silence, a defensive strategy which employees take to maintain the existing resources. The perceptions of organizational politics increase employees' anxiety, and the anxiety make the employee get feared and enhance their protection consciousness, resulting in a defensive silence.

Finally, the study considers the contingency factors of leader-member exchange relationship when discussing the effects of abusive supervision. The results show that the quality of leadermember exchange relationships would affect the effect of abusive supervision. The better the quality leader-member exchange relationship is, the positive influence on perceptions of organizational politics that abusive supervision play is weaker. This is actually consistent with Chinese culture where Chinese people attach importance to interpersonal relationship and pay much attention to maintain relationships and "circle culture". When the "in-group" suffer the abusive supervision, they will consider it as a strict requirement. However, when the "out-group" suffer the abusive supervision, they will immediately detect this behavior and increase their perceptions of organizational politics, taking some actions to deal with it. The "out-group" are sensitive to the words and deeds of their leaders. 


\section{Theoretical Implications}

This study reveals the crucial influence mechanism of abusive supervision on employee silence. It thereby provides an essential inspiration for enterprises to reduce the harmfulness of abusive supervision and to prevent employee to keep silent. Research on abusive supervision and employees' explicit behavior has been conducted by predecessors, but seldom from a subtle way especially from an organizational politics perspective. This study is the first to discuss the mediating effects of perceptions of organizational politics between abusive supervision and employee silence. This study also takes into account the special cultural environment in China, considering the moderating effect of LMX. This study further enriches the development of leadership theory and provides a new perspective to reveal the "black box" relationship between organizational leaders who exhibit abusive supervision behavior and employee silence.

\section{Practical Implications}

The harm caused by abusive supervision has been recognized in both academic and management practices. The conflicts caused by this negative style of leadership will be even worse, as the new generation employees gradually become the main power in the workplace. It is necessary to take effective measures to avoid this negative style of leadership. Following managerial implications have been proposed.

A strict monitoring mechanism should be established to assess the supervisors so that it can avoid the leaders to misuse their authority or abuse their subordinates. At the same time, those who have a tendency to abusive subordinates should be put on record and should be educated and trained. In addition, the enterprise should connect abusive supervision with leaders' performance bonus, in other words, the abusive behavior will directly affect individual performance.

The organization should establish clear communication channels and encourage the staffs to express their opinions. As we know, abusive supervision is a kind of subjective perception or evaluation about their leaders by subordinates, thus different subordinates may have different feelings even on the same behavior. Especially, in the organization, the leaders should pay more attention to the "out-group", because they are more sensitive to leaders' behavior. On the one hand, the leaders should actively listen and understand subordinates' true thoughts, dissolve the misunderstandings in time and reduce employees' perceptions of organizational politics. On the other hand, the organization should let employees have the chances and channels to express their thoughts, such as setting up a suggestion box or leaders regularly visiting day etc. Thus, when the subordinates cope with the abusive behavior, they could report the situation to a higher supervisor rather than keep silent.

The organization can also take some measures from the human resources management practices. Firstly, the organization should avoid selecting those who have domestic violence or easy to get irritable as a leader, because they have a high risk to abuse their subordinates. Secondly, for those who are already in positions of leaders, if they have a tendency to abusive subordinates, appropriate training should be given to enable them to recognize the feelings of being abused. For example, the leader and the employee can switch roles with each other, so that the leaders can know the feeling of being abused. Lastly, in the process of appraising leaders, the 
organization should increase the proportion that subordinates evaluate their leaders. To some extent, it could make the leader respect employee's self-esteem and psychological feelings, and reduce the abusive behavior more effectively.

The manager should make examples, pay attention to their words and deeds, and try the best to avoid organizational politics. At the same time, the leader should also investigate into the causes of perceptions of organizational politics and restrict the existing organizational politics.

\section{References}

Aiken, L. S., \& West, S. G., \& Reno, R. (1991). Multiple regression: Testing and interpreting interactions. London, UK: SAGE.

Aryee, S, Chen, Z. X., Sun, L. Y., \& Debrah, Y. A. (2007). Model. Journal of Applied Psychology, 92(1), $191-201$.

Dyne L. V., Aiig, S., \& Boterolc, (2003). Conceptualizing employee silence and employee voices multidimensional constructs. Journal of Management Studies, 4(6), 1359-1392.

Hobfoll S. E. (1989). Conservation of resources: A new attempt at conceptualizing stress. American Psychologist, 44, 513-524.

Hoobler, J., \& Brass, D. (2006). Abusive supervision and family undermining as displaced aggression. Journal of Applied Psychology, 91(5), 1125-1133.

Liu W., Liao J. Q., \& Zhang P. C. (2012). Inner-mechanisms between abusive supervision and employee creativity. Industrial Engineering and Management, 17(5), 112-118.

Liu, X., \& Liu, J. (2014). The influences about abusive supervision based on organizational politics. Economical Science, 12(5), 118-128.

Ma, C. (2005). The effect of perceptions of organizational politics on human resource management. Guangzhou, China: Jinan University.

Morrison E. W., \& Milliken F. J. (2000). Organizational silence: A barrier to change and development in a pluralistic world. Academy of Management Review, 25(4), 706-731.

Priesemuth, M., Schminke, M., Ambrose, M. L., \& Folger, R. (2014). Abusive supervision climate: A multiplemediation model of its implication on group outcomes. Academy of Management Journal, 57(5), 15131534.

Tepper, B. J. (2000). Consequences of abusive supervision. Academy of Management Journal, 43(2), $178-190$.

Tepper, B. J., Henle, C. A., Lambert, L. S., Giacalone, R. A., \& Duffy, M. K. (2008). Abusive supervision and subordinates' organization deviance. Journal of Applied Psychology, 93, 721-732.

Wang, H., \& Niu, X. Y. (2004). Multi-dimensional leader-member exchange (LMX) and its impact on task performance and contextual of performance of employees. Acta Psychologica Sinica, 36(2), 179-185.

Whitman, M. V. (2014). Abusive supervision and feedback avoidance: The mediating role of emotional exhaustion. Journal of Organizational Behavior, 35, 38-53.

Wu, L. Z., Liu, J., Leung, A., \& Wu, W. (2013). Abusive supervision and team performance: Mediating effects of team communication and efficacy. Management Review, 32(8), 151-159.

Wu, X. C. (2001). The effect of perceptions of organizational politics on organizational commitment. Guangdong, China: Sun Yat-Sen University.

Wu, Z. Y. (2005). Original value and survival dilemma of immaterial cultural tour resources in Huizhou area. China Population Resources \& Environment, 15(4), 127-130.

Yukl, G. (2002). Leadership in organizations. Upper Saddle River, NJ: Prentice Hall.

Zheng, X. T., Ke, J. L., Shi, J. T., \& Zheng, X. S. (2008). Survey on employee silence and the impact of trust on it in China. Acta Psychologica Sinica, 40(2), 219-227. 